\title{
Leadership in Conditions of Industry 4.0
}

\author{
Diana Puhovichová1, ${ }^{*}$, Nadežda Jankelová ${ }^{1}$ \\ ${ }^{1}$ University of Economics in Bratislava, Faculty of Business Management, Management Department, \\ Dolnozemská cesta 1, Bratislava, Slovakia
}

\begin{abstract}
Nowadays, technological development and innovation play an important role in every enterprise. This is particularly reflected in the increase in competitiveness of any enterprise. It is Industry 4.0 that wants to lead to possible profound changes in several areas that go beyond the industrial sector. Leadership is essential for the successful promotion of a culture of innovation. Therefore, leaders and leadership style play a key role in the paradigm shift towards Industry 4.0. The aim of the theoretical research is to present the key characteristics of Leadership 4.0, the necessary skills of Leaders 4.0 and to introduce appropriate leadership styles in the context of Industry 4.0. Through the available domestic and foreign literature, we have provided a theoretical reality of what leadership in Industry 4.0 conditions should look like. According to results, that we have found out during theoretical research, we have reached conclusions that the core attributes of Leadership 4.0 include communication, knowledge and understanding, well-set standards and methods, coaching, expectations, openness and transparency, trust, employee orientation, and a culture of mistakes. We also pointed out that within the presented leadership matrix, the digital leader represents the most appropriate style within Industry 4.0, and among other things, this leader should dispose of cognitive skills, business skills, interpersonal skills, and strategic skills.
\end{abstract}

\section{Introduction}

Increasing global competition is forcing businesses to expand and personalize their product and service offerings to meet the needs of their customers through mass customization. Due to the volatile and highly competitive market, companies are required to continuously increase the flexibility of their business processes. In fact, technological advances are at the root of the Industry 4.0 concept, which first emerged at Hannover Messe in 2011, and was initiated by a German government to improve the performance of the industrial sector, and to cope with the increased complexity of manufacturing systems by improving systems integration. In research, Industry 4.0 refers to a set of concepts and technologies that enable decentralized decisions based on real-time connectivity and communication between systems and machines to develop and improve processes, products, and services [16]. This change is driven by various ongoing global megatrends such as globalization, urbanization, individualization, and demographic changes that will

\footnotetext{
* Corresponding author: diana.puhovichova@euba.sk
} 
significantly affect the entire business environment in the future. On one hand, the increase in globally interconnected business activities will increase complexity in production networks. On the other hand, volatile demand and customized products will additionally influence production and planning processes. These demanding requirements will force businesses to adapt their entire operations, including structures, processes, and products [2].

The process of transforming an enterprise to Industry 4.0 conditions depends on the adaptation of leadership to the Industry 4.0 era - a phenomenon often characterized as leadership 4.0. For a successful transformation to Leadership 4.0, managers need to be qualified and promoted to meet and be prepared for such challenges [10]. It is therefore evident that a culture of openness to change in a business flows from the right leadership.

In the following theoretical research, we will discuss the impact of Industry 4.0 on leadership in enterprises. We will provide a comprehensive concept of what leadership in Industry 4.0 should look like so that companies are able to adapt to the conditions of the new phenomenon. Through professional literature and articles, we will determine the basic concepts that will give us a better understanding of the mentioned issue.

\section{Theoretical Background}

\subsection{Industry 4.0}

The development of digitalization over the last few decades has led to the so-called Fourth Industrial Revolution. This revolution is also known as Industry 4.0. Engineer and economist Klaus Schwab, founder and president of the World Economic Forum has declared that Industry 4.0 will fundamentally change the way we live. The new phenomenon aims to combine the strengths of traditional industries with state-of-the-art Internet technologies. According to experts, this industrial revolution is based on the Internet and enables communication over large networks between humans and cyberphysical systems [5,7]. Industry 4.0 is thus defined as the fourth industrial revolution, a new level of organization and control of entire value chains throughout the product lifecycle. This cycle includes the fulfillment of individualized customer requirements and extends from idea, actual order, development and production, delivery to the customer and recycling. The key is the availability of all necessary information in real time through the interconnection of all instances involved in value creation, as well as the ability to derive the best possible value stream based on the resulting data. By linking people, objects and systems, dynamic, real-time optimized, self-organizing, inter-enterprise value networks are developed that can be optimized based on various criteria such as cost, availability, and efficiency of resources [2].

PwC's study, "Industry 4.0: Building Digital Enterprise", shows that the technology needed to implement Industry 4.0 is ready, the problem is the lack of digital culture, vision, training, and a shortage of experts [3]. From the above, it is evident that these problems can be solved by the right leadership.

For the successful implementation of the enterprise transformation to Industry 4.0 conditions, nine core technologies are required, which must be part of the entire enterprise system. The core enabling technologies that make up the Industry 4.0 concept include: big data and analytics, autonomous robots, simulations, horizontal and vertical integration of systems, the Internet of Things, cybersecurity, cloud computing, additive manufacturing, and augmented reality. The following table shows all the above technologies that form the basis for the successful operation of an enterprise in the conditions of Industry 4.0.

Table 1 Pillars of Industry 4.0 


\begin{tabular}{|c|c|}
\hline \multicolumn{2}{|r|}{ Nine pillars of Industry 4.0} \\
\hline $\begin{array}{l}\text { Big Data and } \\
\text { Analytics }\end{array}$ & $\begin{array}{l}\text { The term Big Data refers to large, diverse, and complex data sets that influence } \\
\text { organizational decision-making in relation to business strategy. Therefore, there is a need to } \\
\text { increase the levels of data and improve technological capabilities that accelerate the } \\
\text { competitiveness of enterprises in the form of increased productivity, innovation. The big } \\
\text { data framework could be described as: data as a tool (solving traditional value chain } \\
\text { problems using existing capabilities), data as an industry (new ventures and the } \\
\text { development of software systems to process big data) and data as a strategy (building data } \\
\text { resources by developing new innovative business models). The process of big data } \\
\text { analytics involves the analysis of large data sets that provide information on customer } \\
\text { preferences, algorithms for correlations, trends, and other information. We can predict } \\
\text { failures through analytics and thus reduce the probability of errors [8]. }\end{array}$ \\
\hline $\begin{array}{l}\text { Autonomous } \\
\text { Robots }\end{array}$ & $\begin{array}{l}\text { Robots are used in the manufacturing industry to solve complex tasks that are not easily } \\
\text { solvable by humans. Current improvements in industries would make the use of robots less } \\
\text { complicated and easy to use. Different human-robot interfaces create a close collaboration } \\
\text { of robot usage and human brain. The use of more industrial robots in factories is } \\
\text { accelerating with Industry } 4.0 \text {. They would have applications in multiple fields such as } \\
\text { manufacturing, logistics, distribution activities and could be controlled remotely by humans } \\
\text { through mutual collaboration [1]. }\end{array}$ \\
\hline Simulation & $\begin{array}{l}\text { Industry } 4.0 \text { simulation refers to the } 3 \mathrm{D} \text { simulation of products, materials and } \\
\text { manufacturing processes that use real-time data to reproduce the physical world in a virtual } \\
\text { model. Operators use simulation to identify weaknesses in their products, test and optimize } \\
\text { machine settings and processes in the virtual world [10]. }\end{array}$ \\
\hline $\begin{array}{l}\text { Horizontal and } \\
\text { vertical integration }\end{array}$ & $\begin{array}{l}\text { Vertical integration refers to flexible and reconfigurable systems inside the manufactory to } \\
\text { the extent that they are fully integrated with each other to achieve agility. Horizontal } \\
\text { integration refers to the integration of partners within supply chains. An industrial network } \\
\text { collects large amounts of data to optimize system performance and send it to the cloud. } \\
\text { This coordination mechanism forms the framework of the smart factory. Therefore, } \\
\text { manufacturing systems are designed as a self-organized structure that integrates each } \\
\text { physical object through smart networks. In addition, cloud-based systems enable vertical } \\
\text { partners to integrate with each other through common platforms. Product and process flows } \\
\text { would be visualized and tracked by members of the supply chain [8]. }\end{array}$ \\
\hline Internet of Things & $\begin{array}{l}\text { The concept of the Internet of Things represents structures that allow objects to } \\
\text { communicate with each other. The IoT is expected to open many economic opportunities } \\
\text { and is considered one of the most promising technologies with great disruptive potential. } \\
\text { The idea was formulated in } 1999 \text { to describe a system in which the material world } \\
\text { communicates with computers (data exchange) using sensors that are everywhere. In this } \\
\text { approach, not only objects but also processes, data, people and even animals or atmospheric } \\
\text { phenomena are treated as variables - a system of all things [17]. }\end{array}$ \\
\hline Cyber Security & $\begin{array}{l}\text { Cybersecurity is another important issue that could have a destructive impact on the } \\
\text { business environment due to the malicious intent of terrorist attacks. For this reason, it is } \\
\text { necessary to find preventable solutions and build defensive systems against the negative } \\
\text { effects of terrorist incidents. There are solutions that destroy cyber terrorist attacks, in the } \\
\text { form of analyzing previous terrorist attacks through "radiation control" before future } \\
\text { attacks occur. In addition, it is important to build a national defense system, and train } \\
\text { employees against cyber-attacks. Although cyber warfare solutions will cost businesses a } \\
\text { significant amount of money, the expected total will ultimately not be high due to the } \\
\text { potential negative effects of attacks [11]. }\end{array}$ \\
\hline Cloud Computing & $\begin{array}{l}\text { Cloud computing is a new parallel and distributed system that consists of interconnected } \\
\text { and virtualized computers used based on service level agreements between the service } \\
\text { provider and customers. It provides significant benefits to businesses by freeing them from } \\
\text { the need to build an underlying hardware and software infrastructure and the associated } \\
\text { investment. Cloud computing and the Internet of Things together improve intelligent } \\
\text { perception and M2M-based communication and ensure efficient use of resources in } \\
\text { production systems [18]. }\end{array}$ \\
\hline Additive & Additive manufacturing, also defined as $3 \mathrm{D}$ printing, deals with the production of \\
\hline
\end{tabular}




\begin{tabular}{|l|l|}
\hline Manufacturing & $\begin{array}{l}\text { customized goods based on customer requirements. The most common method is the } \\
\text { prototype and 3D printing method to produce small batches, thereby gaining the advantage } \\
\text { of smaller inventories and overproduction [8]. }\end{array}$ \\
\hline Augmented reality & $\begin{array}{l}\text { Augmented reality is defined as an interactive technology that enables a correspondence } \\
\text { between a virtual world and its users, with the virtual world being used as part of the real } \\
\text { world [8]. The technology enables the delivery of information in real time. A typical } \\
\text { example is virtual reality glasses, which can be used, for example, to train employees in an } \\
\text { enterprise [10]. Augmented reality provides control of users' movements using sensor } \\
\text { technology to control certain tasks [8]. }\end{array}$ \\
\hline
\end{tabular}

We share the view of Črešnar and Nedelko [6] that the above-mentioned technologies will bring significant changes in the enterprise, but they are not only focused on the hard, technological aspects, but the organizational environment is expected to become more multicultural, multidisciplinary, agile, collaborative, and open, which will also affect the soft aspects related to people. As a result of these changes, the question of what leadership in Industry 4.0 should look like: "What values, qualities and attributes leaders should dispose of?"; or "How to get to the forefront in the Industry 4.0 era?"

\subsection{Leadership 4.0}

Leadership focuses on the behavior of senior executives, which sets the general framework in the business and influences the corporate culture, without focusing on the individuals of the business. These aspects are applicable to every employee in the company and have an impact on customers, suppliers, and partners. However, the question is how the leadership of enterprises can be transformed to introduce new business models and new ways of working brought about by digitalization. The solution lies in the implementation of so-called digital leadership, also known as leadership 4.0 [4].

Digital leadership (leadership 4.0) is fast, cross-cutting, team-based, and collaborative leadership with a strong focus on innovation. The leader's personal competencies, his or her mindset, as well as his or her ability to apply new methods and tools, such as design thinking, are crucial dimensions for leaders. Design thinking is a methodology used by designers to solve complex problems and find desirable solutions. Design thinking is solution-focused and action-oriented thinking aimed at creating a preferred future. In business management, it could be used as a step-by-step process to find and implement solutions that increase profits, efficiency, and customer satisfaction; and to keep the business ahead of the innovation curve. Industry 4.0 requires businesses to think in new ways [14].

This phase of digital transformation is very demanding and full of challenges that require non-traditional leadership skills and approach to compete in this situation for the survival of companies. For example, Apple Inc. is the most innovative company; this is not due to the technical skills of CEO Steve Jobs, but to his leadership style. Similarly, Microsoft Corporation owes its success to Bill Gates' different leadership style. Amazon.com is one of the early adopters of 4.0 technologies with a net worth of $\$ 150$ billion. In addition, the second largest company, Adidas is increasing its use of artificial intelligence (AI) technologies in products and is using 3D printing. Company executives have expressed their belief that Change 4.0 is mandatory for those who understand this digital massive wave. In the United States, the non-profit Smart Manufacturing Leadership Coalition (SMLC) is pushing for technological transformation as it has found that leaders understand global competitiveness and challenges. In addition, a PWC report analyzed from 235 European companies that only $3.3 \%$ of leaders are investing in Industry 4.0 because they assume that digitalization is mandatory for the sustainability of their business [19]. 
CEO Rajeev Peshawaria of ICLIF (Leadership \& Governance Centre, Malaysia), after analysing 255 definitions and real case studies, developed a leadership formula [15], as shown below.

Leadership $=$ (charisma + personality) $x$ (power and authority) + (skills and competencies + best practices) $x$ (cognitive intelligence + emotional intelligence)

In addition, the book Open Source Leadership [15] provides a definition of leadership from the perspective of the Fourth Industrial Revolution, confirming that in the wave of digital disruption, leadership is the art of harnessing human energy to create a better future.

In this world of constant change in technology, mergers, increasing global competitiveness, diversity of ideas, along with a mix of different opinions, experiences and digitalization, the forms of business must be based on leadership that is in everyone's interest. In the fourth industrial revolution, leadership is not about power and status, but about a fundamental change of mindset. We need leadership that will prevent the world from becoming a victim of Industry 4.0. Indian Prime Minister Modi said: "The administrative mind-set of the last century will not help us move forward into the new century". Former Malaysian minister Datuk Seri Idris Jusoh said: "Leaders should seize the potential opportunities that Industry 4.0 brings with great responsibility and wisdom by providing digital leadership to their institutions [19].

We share Zakaria and Nasir's view that forward-looking leaders have the potential to anticipate future changes and, as a result, can prepare businesses to successfully fight against Industry 4.0. The Fourth Industrial Revolution undoubtedly has the power to change many things from the physical world to the digital world. However, one thing is for sure, leaders need to fully prepare because the old ways are no longer enough for businesses to operate in Industry 4.0 conditions.

\section{Research design}

The aim of the theoretical research is to point out the importance of the modern phenomenon Industry 4.0, which blurs the boundaries between physical, biological, or digital spheres, and to show its impact in leadership through literature and scientific articles. The object of the theoretical research is the leadership of enterprises that are affected by the growing impact of Industry $4.0 \mathrm{We}$ focus on the issue of values of digital leadership in conditions of Industry 4.0, the basic characteristics of Leader 4.0 and the leadership styles that should be applied in enterprises in conditions of Industry 4.0.

To analyze the topic, we will use accessible domestic and foreign sources that describe in detail the issues of Industry 4.0, the basic technologies that form its concept, the essence of leadership and leadership 4.0, and the emerging changes in the field of leadership, which are caused by the impact of Industry 4.0. Through the information gathered, we will complete a theoretical elaboration of the issue.

To elaborate the theory, we used the basic scientific methods: analysis, synthesis, generalization, as well as induction and deduction. From the acquired information, we have created a theoretical knowledge base on leadership that reflects the needs of Industry 4.0.

By elaborating the mentioned issues, we developed the following research questions:

- What core values should business leadership dispose of in conditions of Industry 4.0 ?

- What should a leader in Industry 4.0 be like? What qualities and skills should leader 4.0 dispose of?

- What business leadership styles are suitable to Industry 4.0 ? 
The research questions were answered in the results and discussion of the theoretical research.

\section{Research results and discussion}

For businesses, leadership plays an important role in Industry 4.0, as changing the way a business is run requires far-reaching strategic decisions at all levels of the enterprise. In this context, future leaders will need to be more responsive to the perceived patterns and signals that Industry 4.0 points to in a constant field of growth, change and opportunity. Therefore, in the following section of the theoretical research, we will offer answers to the research questions, providing the necessary characteristics of leadership in Industry 4.0 terms:

\section{What core values should business leadership dispose of in conditions of Industry 4.0?}

Based on the characteristics of Industry 4.0 and Industry 4.0-compliant leadership outlined in Chapter 2, the most influential attributes of successful leadership of the company and employee are:

1. Communication: intensive communication between management and employees

2. Knowledge and understanding: knowledge of the significance of the changes initiated by digitization

3. Methods and standards: appropriate methods and standards implemented within the corporate culture and identity

4. Coaching: Managers with coaching skills who become good role models for the company's employees

5. Expectations and orientation: guiding the level of management and meeting the expectations of the company

6. Openness and transparency: an open and transparent atmosphere between employees and management

7. Trust: trust and freedom in the workplace regarding the time, place, and content of work

8. Employee focus: Focus on employee growth and well-being

9. Bug culture: living an open bug culture in the enterprise that enables the innovation needed in an Industry 4.0 environment [4].

What should a leader in Industry 4.0 be like? What qualities and skills should dispose of?

Digital technologies have an impact not only on the information technology field, but also on business management. Leadership 4.0 is leadership in the age of Industry 4.0, which is handled by Leaders 4.0 These leaders are called digital leaders. Not every leader in an enterprise is also a digital leader. Germany, as a showcase country where Industry 4.0 originated, is thriving when it comes to Industry 4.0 and the Internet of Things. However, this does not mean that the managers of these (German) enterprises are automatically digital leaders. What makes a digital leader a leader is not the area in which the enterprise operates. It's a matter of leadership style and the ability of these leaders to inspire their employees to innovate and to sustain and develop their ideas. We consider the following elements to define digital leaders: organizational goals (ability to move from fixed cycles of employee performance appraisal to the ability to understand that situations determine the need for employee appraisal, together with the ability to establish routine feedback procedures), people (ability to allocate tasks based on the situation and the competence of the team; linking the skills of managers and employees to create the competence of network intelligence), change (high level of willingness and capability for change; fostering a high 
level of agility between market, customer, partners and employees), output (the ability to manage processes, evaluate tasks and results with teams, use resources in accordance with competencies - cross-hierarchically and cross-functionally - instead of controlling contracts, resource plans and evaluating results within project boundaries, as traditional leaders do), mistakes and conflicts (creating an open atmosphere with the effect of learning from mistakes, and an atmosphere of cooperation in conflict resolution), communication (the ability to create a transparent framework for information distribution), as well as innovation (the knowledge that innovation can be learned; the ability to transform old structures through the use of multidisciplinary teams and creative processes in a flexible working environment) [14].

The acquisition and refinement of leadership skills is influenced by individual differences in cognitive capacity, personality traits, temperament, abilities to control emotions, identities and values resulting from both factors, cultural context, and personal experiences [12].

According to Mumford [13], leaders in Industry 4.0 conditions should be equipped with the following leadership skills, which can be divided into 4 groups: 1) cognitive skills that executive leaders need to understand the required complex behavioral patterns, including creative thinking, decision making, and strategic problem solving; 2) interpersonal skills, which are defined as goal-oriented behaviors used in personal interactions to achieve a desired state of affairs; 3) business skills include organizing, negotiating, and managing personal, financial, and material resources; 4) strategic skills, which are associated with conceptualizing the mission and vision of the company. These four groups of leadership skills consist of other relevant skills, which are listed in the table below.

\section{COGNITIVE SKILL INTERPERSONAL BUSINESS SKILL STRATEGIC SKILL} SKILL

\begin{tabular}{|c|c|c|c|}
\hline Speaking & Social perceptiveness & Operations analysis & Visioning \\
\hline Active listening & Coordination & $\begin{array}{ll}\text { Management } & \text { of } \\
\text { personnel resources } & \end{array}$ & Systems perception \\
\hline Writing & Negotiation & $\begin{array}{l}\text { Management of financial } \\
\text { resources }\end{array}$ & System evaluation \\
\hline Reading comprehension & Persuasion & $\begin{array}{l}\text { Management of material } \\
\text { resources }\end{array}$ & $\begin{array}{l}\text { Identification } \\
\text { downstream } \\
\text { consequences }\end{array}$ \\
\hline Active learning & & & $\begin{array}{l}\text { Identification of key } \\
\text { causes }\end{array}$ \\
\hline Critical thinking & & & $\begin{array}{l}\text { Problem identification } \\
\text { Solution appraisal }\end{array}$ \\
\hline
\end{tabular}

\section{What business leadership styles are suitable to Industry 4.0?}

Oberer and Erkollar's study [14] developed a two-dimensional Leadership 4.0 matrix that depicts the types of styles that can be applied in companies in Industry 4.0 conditions. It will be based on the orientation towards innovation and technology and towards caring for people. The matrix is divided into four quadrants. In each quadrant, one leadership style that is best suited the particular leader. The $\mathrm{X}$ axis describes the capabilities of the individual and focuses on the orientation towards technology and innovation. The Y axis defines the leader's people focus. For example, a person with a high level of education in a technology-related field is likely to want a technology-oriented leadership style, such as TL (Technology Leader 4.0) or DL (Digital Leader 4.0, if they also have a high employee orientation). A person who generally seeks employee engagement in decision making is more likely to prefer an employee-centric leadership style such as SL (Social Leader 4.0). A leader who is without a specific orientation, neither to people's interests nor to 
technology/innovation, with a low orientation to people as well as a low orientation to technology/innovation, then we talk about the so-called FL (Freshmen leader 4.0). The following table shows the different styles that are part of the two-dimensional leadership 4.0 matrix.

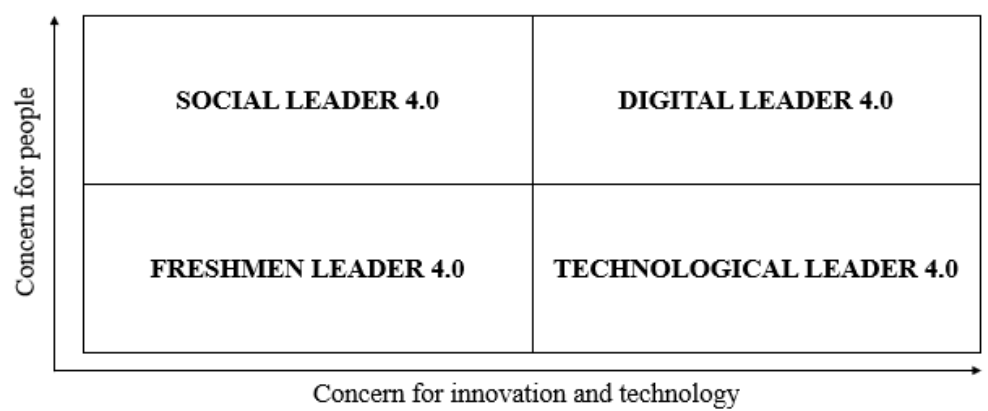

Fig. 1. Leadership matrix

FL focuses on traditional structures with a primary focus on the end product; it has no focus on employees; customer needs are of negligible importance, as well as for new technologies. SL disposes of the ability to create a friendly atmosphere for employees regardless of innovation and technology. Employee support is important. TL focuses on the ability to determine how new technologies can be leveraged to provide a higher value. Innovation orientation and low employee focus prevails. DL focuses on the ability to understand how technology affects people, and how the organizational model aligns with human nature. These are equally essential elements of digital leadership. The digital leader "Leader 4.0" is the most productive style of Leadership 4.0.

\section{Conclusion}

After explaining the importance of leadership in the digital age, this article reveals that digitized enterprises need a new type of leadership, called leadership 4.0. This should foster an agile environment that is essential for driving innovation forward quickly and creating higher customer satisfaction. Through leadership 4.0, on one hand, the culture of enterprises is being influenced and, on the other hand, the work of enterprises itself is being influenced. It is up to the companies whether the leadership is able and willing to adapt to the new phenomenon of Industry 4.0 and thus sustain and develop their competitiveness.

Through the literature and professional scientific articles, we have highlighted the essence of leadership in Industry 4.0 conditions, thus fulfilling the main objective of the theoretical research. We have also provided answers to the above research questions, in which we have noted what basic attributes leadership should disposes of, we have listed the basic and necessary characteristics of a leader 4.0, and we have provided an overview of appropriate leadership styles in the form of a leadership 4.0 matrix.

\section{Acknowledgement}

This paper is a partial output of the VEGA ME SR project No.1/0017/20 Changes in the application of managerial functions in the context of the fourth industrial revolution and adaptation processes of enterprises in Slovakia. And a partial output of the Project for 
young teachers, researchers, and $\mathrm{PhD}$ students No. I-21-111-00 The impact of the fourth industrial revolution on managerial functions.

\section{References}

1. M. Aiman, et al. Industry 4.0: A review on industrial automation and robotic. Jurnal Teknologi. Sciences \& Engineering 78, pp. 137-143 (2016)

2. C. J. Bartodziej, The concept industry 4.0. The concept industry 4.0, pp. 27-50 (2017)

3. A. Bencsik, Challenges of Management in the Digital Economy. International Journal of Technology 11, pp. 1275-1285 (2020)

4. S. Bolte, J. Dehmer, J. Niemann, Digital Leadership 4.0. Acta technica napocensis - Series: Applied mathematics, mechanics, and engineering 61, pp. 637-646 (2018)

5. M. Brettel, N. Friederichsen, M. Keller, M. Rosenberg, How Virtualization, Decentralization and Network. Building Change the Manufacturing Landscape: An Industry 4.0 Perspective. International Journal of Information and Communication Engineering 8, pp. 37-44 (2014)

6. R. Črešnar, Z. Nedelko, Understanding Future Leaders : How are Personal Values of Generations Y and Z Tailored to Leadership in Industry 4.0? Sustainability 12, pp. 4417 (2020)

7. N. Daneshjo, M. Majerník, E. Danishjoo, E, More Exact Approaches to Modernization and Renewal of the Manufacturing Base. TEM Journal 6, pp. 445449 (2017)

8. G. Erboz, How to Define Industry 4.0: The Main Pillars of Industry 4.0. Managerial trends in the development of enterprises in globalization era, pp. 761767, 2017.

9. S. Helming, F. Ungermann, N. Hierath, N. Stricker, G. Lanza, Development of a training concept for leadership 4.0 in production environments. Procedia Manufacturing 31, pp. 38-44 (2019)

10. M. Chiarvesio, R. Romanello, Industry 4.0 Technologies and Internationalization: Insights from Italian Companies. International Business in the Information and Digital Age 13, pp. 357-378 (2018)

11. H.S. Cho, T.H. Woo, Cyber security in nuclear industry - Analytic study from the terror incident in nuclear power plants (NPPs). Annals of Nuclear Energy 99, pp. 47-53 (2017)

12. R. H. Lord, Identity, deep structure and the development of leadership skill. The leadership Quarterly 16, pp. 591-615 (2005)

13. T. Mumford, M. Campion, F. Morgeson, The leadership skills strataplex: Leadership skill requirements across organizational levels. The Leadership Quarterly 18, pp. 154-166 (2007)

14. B. Oberer, A. Erkollar, Leadership 4.0 : Digital Leaders in the Age of Industry 4.0. International journal of organizational leadership 7, pp. 404-412 (2018)

15. R. Peshawaria, Minimum supervision, maximum performance. Leader to Leader, 87, pp. 42-47 (2018) 
16. S. Richard, R. Pellerin, J. Bellemare, N. Perrier, A business process and portfolio management approach for Industry 4.0. Business Process Management Journal 27, pp. 505-528 (2021)

17. M. F. Skender, I. Ali, Digitalization and Industry 4.0 (2019)

18. A. Ustundag, E. Cevikcan, Industry 4.0 : Managing the Digital Transformation. Industry 4.0 : Managing the digital transformation, pp. 1-286 (2018)

19. N. Zakaria, A. Nasir, A. Akhtar, Are the Leaders Ready to Embrance Industry 4.0 ? Journal of Advanced Research in Dynamical and Control Systems 11, pp. 543-549 (2019) 